\title{
How well do blood folate concentrations predict dietary folate intakes in a sample of Canadian lactating women exposed to high levels of folate? An observational study
}

\author{
Lisa A Houghton 1,2, Kelly L Sherwood ${ }^{2,3}$ and Deborah L O'Connor*2,3
}

Address: ${ }^{1}$ School of Nutrition \& Dietetics, Acadia University, 12 University Avenue, Wolfville, NS, B4P 2R6, Canada, ${ }^{2}$ Department of Nutritional Sciences, University of Toronto, Toronto, ON, M5S 3E2, Canada and ${ }^{3}$ Department of Clinical Dietetics and Physiology and Experimental Medicine Program, The Hospital For Sick Children, 555 University Avenue, Toronto, ON, M5G 1X8, Canada

Email: Lisa A Houghton - lisa.houghton@acadiau.ca; Kelly L Sherwood - kellysherwood@yahoo.ca; Deborah L O'Connor* - deborah_l.oconnor@sickkids.ca

* Corresponding author

Published: 25 October 2007

BMC Pregnancy and Childbirth 2007, 7:25 doi:10.1 I86/147/-2393-7-25

Received: 25 January 2007

Accepted: 25 October 2007

This article is available from: http://www.biomedcentral.com/I47I-2393/7/25

(c) 2007 Houghton et al; licensee BioMed Central Ltd.

This is an Open Access article distributed under the terms of the Creative Commons Attribution License (http://creativecommons.org/licenses/by/2.0), which permits unrestricted use, distribution, and reproduction in any medium, provided the original work is properly cited.

\begin{abstract}
Background: In 1998, mandatory folic acid fortification of white flour and select cereal grain products was implemented in Canada with the intention to increase dietary folate intakes of reproducing women. Folic acid fortification has produced a dramatic increase in blood folate concentrations among reproductive age women, and a reduction in neural tube defect (NTD)-affected pregnancies. In response to improved blood folate concentrations, many health care professionals are asking whether a folic acid supplement is necessary for NTD prevention among women with high blood folate values, and how reliably high RBC folate concentrations predict folate intakes shown in randomized controlled trials to be protective against NTDs. The objective of this study was to determine how predictive blood folate concentrations and folate intakes are of each other in a sample of well-educated lactating Canadian women exposed to high levels of synthetic folate.
\end{abstract}

Methods: The relationship between blood folate concentrations and dietary folate intakes, determined by weighed food records, were assessed in a sample of predominantly university-educated lactating women $(32 \pm 4$ yr) at $4-(n=53)$ and 16 -wk postpartum $(n=55)$.

Results: Median blood folate concentrations of all participants were well above plasma and RBC folate cut-off levels indicative of deficiency $(6.7$ and $317 \mathrm{nmol} / \mathrm{L}$, respectively) and all, except for 2 subjects, were above the cutoff for NTD-risk reduction ( $>906 \mathrm{nmol} / \mathrm{L})$. Only modest associations existed between total folate intakes and plasma $(r=0.46, P<0.00 \mathrm{I})$ and RBC $(r=0.36, P<0.0 \mathrm{I})$ folate concentrations at I6-wk postpartum. Plasma and RBC folate values at 16 -wk postpartum correctly identified the quartile of folate intake of only 26 of $55(47 \%)$ and 18 of $55(33 \%)$ of subjects, respectively. The mean RBC folate concentration of women consuming $|5|-4 \mid 0 \mu g /$ $d$ of synthetic folate $\left(2^{\text {nd }}\right.$ quartile of intake) did not differ from that of women consuming $>410 \mu g / d$ ( $3^{\text {rd }}$ and $4^{\text {th }}$ quartile).

Conclusion: Folate intakes, estimated by food composition tables, and blood folate concentrations are not predictive of each other in Canadian lactating women exposed to high levels of folate. Synthetic intakes > I5I$410 \mu \mathrm{g} / \mathrm{d}$ in these women produced little additional benefit in terms of maximizing RBC content. More studies are needed to examine the relationship between blood folate concentration and NTD risk. Until data from such studies are available, women planning a pregnancy should continue to consume a daily folic acid supplement of $400 \mu \mathrm{g}$. 


\section{Background}

Folic acid supplementation during the periconceptional period is effective in reducing the risk of neural tube defects (NTDs) [1-5]. However, the proportion of Canadian women that report consuming a folic acid-containing supplement during the periconceptional period is low ranging between $17-28 \%$ [6-9]. Similar rates are documented even among women who are knowledgeable about the health benefits of consuming folic acid during this life-stage [8]. As a result, mandatory folic acid fortification of white flour and select cereal grain products was implemented in 1998 in Canada with the intention to increase the dietary folate intakes of reproducing women by 80 to $100 \mu \mathrm{g} / \mathrm{d}$ [10]. Indeed folic acid fortification has resulted in a dramatic increase in blood folate concentrations in North America, and a significant reduction in NTD-affected pregnancies (19 - 78\%) [7,11-14].

In response to the improved blood folate concentrations of reproductive age women, many health care professionals are requesting direction on how aggressively they should promote folic acid supplementation among patients with high blood folate concentrations during the periconceptional period. The research literature shows many Canadian women post-fortification have red blood cell (RBC) folate concentrations approaching or exceeding $906 \mathrm{nmol} / \mathrm{L}[7,15]$, a value in early pregnancy shown to be an indicator of a reduced risk for NTDs [16-18]. For example, we previously reported median RBC folate concentrations $\geq 3000 \mathrm{nmol} / \mathrm{L}$ during the $3^{\text {rd }}$ trimester of pregnancy in a sample of well-educated Canadian women [15].

It must be acknowledged that the body of evidence supporting a relationship between folic acid supplementation during the periconceptional period and the risk of an NTD-affected pregnancy is considerably more robust than that of the association between blood folate concentrations and NTD risk $[1-5,19]$. Nonetheless, it is hard to argue against the logic that RBC folate concentrations, a measure of tissue folate stores, are unlikely to be elevated unless dietary folate intakes are similarly high [20]. For example, in controlled feeding studies preceded by a folate depletion phase of 2-7 weeks, serum and RBC folate concentrations of reproductive age women reflect the folate content of their diet (folate depletion, 400, 800 $\mu \mathrm{g} /$ day dietary folate equivalents [DFE]) [21-25]. Pre-folic acid fortification of the food supply, we reported a weak association between RBC folate concentrations and dietary folate intakes in young women not consuming a folic acid-containing supplement $(r=0.23, P<0.05)$ [26]. This association improved when young women consuming supplemental folic acid were included in the analyses $(\mathrm{r}=$ $0.50, P<0.01)$, suggesting that as the proportion of folate intake from synthetic folic acid increases, so might the predictive value of blood folate measures in determining folate intake. We speculated that folic acid added as a fortificant to food may likewise strengthen this association given its stability, and improved precision and accuracy of measurement, compared to endogenous folates which are normally trapped within cellular matrices, and need to be converted to a microbiologically assayable form. Second, inclusion of women known to consume supplements and fortified foods is likely to increase the range of exposure to folate which may also strengthen the association between blood folate concentration and folate intake. In contrast, if the relationship between blood folate concentration and folate intake is no longer linear at higher levels of exposure or the quality of the food composition tables has deteriorated given the variability in mandated versus actual levels of folic acid fortification, the association between blood folate concentration and dietary folate intake may not have improved.

Lactation is an opportune time to investigate the predictive value of blood folate concentrations in determining dietary folate intake as (1) women are clearly at a reproductive stage of their life cycle; (2) requirements for folate are elevated [27]; (3) vitamin supplement use is common. Therefore, the objective of this study was to examine whether, or not, blood folate concentrations, and dietary and synthetic folic acid intakes are predictive of each other in a sample of affluent, well-educated lactating women exposed to high levels of folate in the form of a supplement and fortificant.

\section{Methods Subjects}

The dietary folate data and blood folate concentrations presented for the observational study presented herein were collected as part of a prospective, randomized control trial designed to assess the efficacy of supplemental [6S]-5-methyltetrahydrofolate ([6S]-5-methylTHF) versus folic acid during lactation $(n=69)$. A detailed description of the study design, procedures and information on the precision and reproducibility of laboratory procedures can be found elsewhere [15]. Briefly, participants were recruited between April 2002 and December 2003. Pregnant women ( $<36 \mathrm{wk}$ gestation) were eligible for the overall study if they were healthy, non-smoking, between the ages of 16 to 40 years and intended to exclusively breastfeed for greater than 4 months postpartum. Subjects were identified by word-of-mouth and through the Motherisk Program, a telephone counseling service, at the Hospital for Sick Children, Toronto, Canada. The Human Ethics Committee of The Hospital for Sick Children approved the study and it was conducted in accordance with the policies and procedures of this institution and the Canadian Tri-Council policy statement on ethical conduct of 
research involving human subjects [28]. Participants gave written, informed consent.

\section{Study Design}

At baseline (36 wk gestation), women were enrolled and a self-administered questionnaire was given to collect information on household income and education level. Participants were then given instructions on the completion of 3-d weighed food records and blood samples were collected. Three-d weighed food records and additional blood samples were collected at 4 - and 16 -wk postpartum ( $\pm 1 \mathrm{wk})$.

In the overall study, women were assigned to receive either a folate supplement ( $400 \mu \mathrm{g} / \mathrm{d}$ of [6S]-5-methylTHF or folic acid) or a placebo within one week of delivery. Subjects were instructed to consume the study capsules daily until 16-wk postpartum and to avoid consuming any other folate-containing supplement during the intervention period. In addition all subjects received a daily folate-free multivitamin and mineral supplement, which contained $1 \mathrm{mg}$ vitamin B6, $3 \mu \mathrm{g}$ vitamin B12 and $4 \mathrm{mg}$ ferrous fumarate (Exact; Pharmetics, Quebec, Canada).

\section{Laboratory procedures}

Blood samples for the analysis of plasma and RBC folate were collected in EDTA-treated tubes at 36 wk gestation and at 4 - and 16-wk postpartum. Plasma folate concentration is an indicator of recent dietary and supplemental folate intake whereas RBC folate concentration is reflective of tissue folate stores [20]. Hematocrit was measured immediately using freshly collected blood with the use of an electronic hematology analyzer (HmX, Beckman Coulter, Miami, Florida). Aliquots $(100 \mu \mathrm{l})$ of whole blood were diluted 10 -fold with ascorbic acid and ddH2O (1\% wt:vol) and incubated at $37^{\circ} \mathrm{C}$ to allow for the deconjugation of folate. Plasma folate and RBC folate concentrations were measured by microbiological assay as described by Molloy and Scott [29]. Plasma homocysteine was measured by high performance liquid chromatography (HPLC) with electrochemical detection according the method of Cole et al. [30].

\section{Dietary Folate Assessment}

Dietary folate intakes were estimated using 3-d weighed food records. Diet records were completed over 2 nonconsecutive days and 1 weekend day by study participants who were trained by 1 of 2 registered dietitians on how to complete food records using an electronic digital scale accurate to $1 \mathrm{~g}$ (CS2000; Ohaus Corporation, Pine Brook, $\mathrm{NJ}$ ). Dietary folate intakes were then tabulated from the diet records using Health Canada's Canadian Nutrient File (CNF), version $2001 \mathrm{~b}$ [31] which has been updated to reflect current mandated Canadian fortification levels and is based on the USDA Nutrient Database for Standard Reference [32]. The CNF reports dietary folate as (1) total dietary folate $(\mu \mathrm{g})$ (sum of naturally occurring folate and folic acid added as fortificant) and (2) folic acid ( $\mu \mathrm{g})$, as a fortificant, separately. Supplemental folate intakes were determined by assessing the difference between the number of capsules dispensed at randomization (within 1 week postpartum) and number of capsules remaining at study completion (16-wk postpartum).

\section{Statistical Analysis}

SAS for WINDOWS (version 9.1; SAS Institute Inc, Cary, NC) was used for statistical analyses and a probability level of 5\% was chosen as the level of statistical significance. The large intra-subject variance in folate intakes were removed using SIDE: Software for Intake Distribution Estimation (version 1.0, Dept of Statistics and Center for Agricultural and Rural Development, Iowa State University, Iowa). The SIDE program operates within SAS for WINDOWS, and generates an estimate of subjects' usual (long-term average) intake by using the distribution of their observed intakes and partially removing the day-today variation in individuals' intakes.

Blood folate concentrations were normalized using logarithmic transformations. Partial correlations $(r)$ were generated between plasma and RBC folate concentrations and folate intakes (total folate and synthetic folate, separately). In addition, the association between RBC folate concentrations at 16-wk postpartum and synthetic folate intake (by quartile assignment for each) was investigated using a one-way analysis of variance and Tukey multiple comparison procedures. RBC folate concentrations measured at study recruitment ( $36 \mathrm{wk}$ gestation) and the form of folate supplement consumed (e.g. [6S]-5-MTHF, folic acid or placebo) during the intervention were entered as covariates in these latter analyses.

The effectiveness of using blood folate values to correctly classify folate intakes was assessed by comparing the quartile assignments for (1) dietary folate intake (total and synthetic folate) and (2) blood folate concentration (plasma and RBC folate) of each subject. When dietary and blood values were assigned to the same quartile, it was concluded that the blood folate value for that subject correctly classified their dietary folate intake. Dietary folate intakes misclassified by only one quartile were considered closely classified, and those misclassified by two or more quartiles were considered misclassified. If no association existed between the assigned quartile of blood folate concentration and dietary folate intake, one would expect $25 \%$ of participants to be correctly classified, $37.5 \%$ to be closely classified and $37.5 \%$ to be misclassified. The actual number of subjects assigned to each quar- 
tile was then compared with expected numbers using a chi-square goodness of fit test with 2 degrees of freedom.

Total dietary folate intakes are expressed in the manuscript, except where indicated, as "Dietary Folate Equivalents" $[\mu \mathrm{g} / \mathrm{d}$ DFE $=$ natural folate, $\mu \mathrm{g}+(1.7 \times$ of supplemental folate, $\mu \mathrm{g})]$ to adjust for the greater bioavailability of synthetic (added as a fortificant or supplemental) folate relative to endogenous sources [27]. For ease of interpretation, no adjustment was made to account for bioavailability of synthetic folate intakes when reported alone (e.g. expressed as $\mu \mathrm{g} / \mathrm{d}$, not $\mu \mathrm{g} / \mathrm{d}$ DFE).

\section{Results \\ Subject Characteristics}

Only those subjects from the overall study who completed 3-d weighed food records and had provided a concomitant blood sample for folate analysis were included in the present analyses ( 4 -wk postpartum, $\mathrm{n}=53 ; 16$ wks postpartum, $\mathrm{n}=55$ ). The mean age of the participants at enrollment was $32.2 \pm 3.8$ y (mean \pm SD). Participants were well-educated (51 of 55 had completed college or university) and predominantly from households with incomes $>\$ 75,000$ per annum. In Ontario, the mean household income in 2001 was estimated be $\$ 60,500$ [33]. Prenatal supplements containing folic acid were used by $98 \%$ (54 of 55) participants during the course of their pregnancy. The average amount of folic acid provided by the supplements prenatally was $923 \pm 239 \mu \mathrm{g} / \mathrm{d}$.

\section{Biochemical indexes}

Median blood folate concentrations during lactation were well above plasma and RBC folate cut-off levels indicative of deficiency (6.7 and $317 \mathrm{nmol} / \mathrm{L}$, respectively) [34] (Table 1). In fact, even by 16-wk lactation, only two of the women had RBC folate values below $906 \mathrm{nmol} / \mathrm{L}$, the value early in pregnancy shown to be an indicator of reduced risk of NTD. RBC folate concentrations of these two subjects were $869 \mathrm{nmol} / \mathrm{L}$ and $822 \mathrm{nmol} / \mathrm{L}$ at 16-wk postpartum. Neither woman consumed a folate supplement during lactation.

Moderate statistically significant correlations $(\mathrm{r}=0.46-$ $0.49, P<0.001)$ were found between total ( $\mu \mathrm{g}$ DFE) and synthetic folate intakes $(\mu \mathrm{g})$ and plasma folate concentrations at 4 - and 16-wk postpartum (Table 2). Weak, but statistically significant correlations $(r=0.31-0.36)$, were found between total ( $\mu \mathrm{g}$ DFE) and synthetic folate intakes $(\mu \mathrm{g})$ at 4 - and 16-wk postpartum and RBC folate concentrations. Regardless of whether, or not, comparisons of folate intake were made with plasma or RBC folate concentration, the strength of the association between synthetic folic acid intake and blood folate values did not differ from the association when all sources of folate intake were considered in the analyses (i.e. naturally occurring + synthetic).

At 16-wk postpartum, plasma and RBC folate concentrations enabled correct prediction of the folate intake quartile assignment for only 47 and $33 \%$ of subjects, respectively (Table 3 ). Further, the percentage of participants correctly classified into their quartile of folate intake by plasma and RBC folate concentration diminished with the removal of supplement users.

Mean RBC folate concentrations were plotted by the quartile of synthetic folic acid intake among lactating women16-wk postpartum to ascertain the mean RBC folate concentration consistent with supplemental folate intakes at or above $411 \mathrm{ug} / \mathrm{d}$ - the top two quartiles of synthetic folic acid intake (Figure 1). Given that women

Table I: Measures of folate status and estimation of folate intakes at 4 and 16 wk postpartum 1

\begin{tabular}{|c|c|c|c|c|}
\hline \multirow{3}{*}{ Variable } & \multicolumn{4}{|c|}{ Daily folate supplementation } \\
\hline & \multicolumn{2}{|c|}{$0 \mu g$} & \multicolumn{2}{|c|}{$400 \mu \mathrm{g}$} \\
\hline & 4 wks $(n=17)$ & 16 wks $(n=18)$ & 4 wks $(n=36)$ & 16 wks $(n=37)$ \\
\hline Plasma folate (nmol/L) & $59(4 I, 85)$ & $46(29,63)$ & $110(74,143)$ & $93(7|| 20)$, \\
\hline RBC folate $(\mathrm{nmol} / \mathrm{L})$ & $2190(1875,2626)$ & $1374(1025,1692)$ & $3024(23 \mid 3,3992)$ & 2090 (I64I, 2527) \\
\hline$\%>906 \mathrm{nmol} / \mathrm{L}^{2}$ & 100 & 89 & 100 & 100 \\
\hline Plasma homocysteine $(\mu \mathrm{mol} / \mathrm{L})$ & $8.8(8.1,9.6)$ & $8.7(8.0,9.4)$ & $9.2(8.6,9.8)$ & $8.9(8.2,9.6)$ \\
\hline \multicolumn{5}{|l|}{ Dietary folate intake } \\
\hline Synthetic folate, $\mu g / \mathrm{d}^{3}$ & $147(75,174)$ & $118(87,15 \mathrm{I})$ & $472(408,511)$ & $450(410,479)$ \\
\hline Dietary folate, $\mu \mathrm{g} / \mathrm{d}$ & $225(193,322)$ & $253(208,320)$ & $27 \mid(2 \mid 4,331)$ & $268(217,326)$ \\
\hline Total folate, $\mu \mathrm{g}$ DFE/d & $48 I(400,56 I)$ & $467(379,543)$ & $1072(983,1163)$ & $1040(953,1135)$ \\
\hline
\end{tabular}

Abbreviations: DFE, dietary folate equivalent $=(\mu \mathrm{g}$ of natural dietary folate $)+(\mu \mathrm{g}$ of folic acid from fortification $\times 1.7)+(\mu \mathrm{g}$ of folate from supplement $\times 1.7)$

1 Median (I st, $3{ }^{\text {rd }}$ quartile); ${ }^{2}$ RBC folate $>906 \mathrm{nmol} / \mathrm{L}$ is associated with low NTD risk [16]. ${ }^{3}$ Synthetic folate $=$ supplemental + folic acid as fortificant 
Table 2: Correlations between folate intakes estimated from a 3day weighed food record vs. blood folate indexes

\begin{tabular}{lccccccc}
\hline & \multicolumn{3}{c}{4 wks } & \multicolumn{3}{c}{16 wks } \\
\cline { 2 - 8 } & $\mathrm{n}$ & $\mathrm{r}$ & $P$-value & $\mathrm{n}$ & $\mathrm{r}$ & $P$-value \\
\hline $\begin{array}{l}\text { Total folatel } \\
\quad \text { Plasma folate }\end{array}$ & 53 & 0.47 & $<0.00 \mathrm{I}$ & 55 & 0.46 & $<0.00 \mathrm{I}$ \\
$\quad$ RBC folate & 53 & 0.32 & $<0.05$ & 55 & 0.36 & $<0.01$ \\
& & & & & & \\
$\begin{array}{l}\text { Synthetic folate } \\
\quad \text { Plasma folate }\end{array}$ & 53 & 0.47 & $<0.001$ & 55 & 0.49 & $<0.0001$ \\
$\quad$ RBC folate & 53 & $0.3 \mathrm{I}$ & $<0.05$ & 55 & 0.36 & $<0.01$ \\
\hline
\end{tabular}

I Total folate $=(\mu \mathrm{g}$ of natural dietary folate $)+(\mu \mathrm{g}$ of folic acid from fortification $\times 1.7)+(\mu \mathrm{g}$ of folate from supplement $\times 1.7)$

2 Synthetic folate $=(\mu \mathrm{g}$ of folate from supplement $)+(\mu \mathrm{g}$ of folic acid from fortification)

with synthetic folate intakes between 151-410 ug/d had mean RBC folate concentrations comparable to those in the upper two quartiles of folate intake suggests that the synthetic folate intakes $>151-410 \mathrm{ug} / \mathrm{d}$ exceed their capacity to incorporate folate into erythropoiesis.

\section{Discussion}

Results from the present study suggest that blood folate concentrations, and folate intake determined by food composition tables, are not reliable predictors of each other in a sample of Canadian lactating women exposed to high levels of folate. In fact, plasma and RBC folate concentrations predicted the correct quartile of folate intake of lactating women in our study less than half of the time. Arguably the best evidence supporting a relationship between folate and NTD-prevention comes from randomized prevention trials in which women were assigned to receive supplemental folic acid ( \pm other vitamins and minerals) during the periconceptional period compared to those that were not $[1,3-5]$. Given the uncertainty of the mechanism(s) of how folate reduces the risk of NTDs, many health care professionals ask how well RBC folate concentrations predict synthetic folic acid intake in order to inform their decision on whether to recommend folic acid supplementation to women with very high blood folate concentrations. While it is conceivable that postfolic acid fortification of the food supply RBC folate concentration may be a better predictor of NTD risk than estimated folate intake, and that folic supplementation is no longer necessary for women with high RBC folate concentrations, randomized controlled trials to confirming this are unlikely to be conducted due to ethical considerations. Other experimental approaches will need to be considered. These known uncertainties together with our data illustrating that blood folate concentrations are not very predictive of folate intake suggest it would be prudent for women even with high blood folate concentrations to consume a folic acid supplement during the periconceptional period for NTD prevention.

Contrary to our original hypothesis, the strength of the association between dietary folate intake, determined by food composition tables, and blood folate concentrations has not improved post-folic acid fortification of the food

Table 3: Percentage of participants correctly, closely or misclassified into quartiles of folate intake compared with classification by blood folate indexes

\begin{tabular}{|c|c|c|c|c|c|}
\hline Variable & $\mathrm{n}$ & Correctly Classified & Closely Classified' & Misclassified ${ }^{2}$ & $P$ value $^{3}$ \\
\hline \multicolumn{6}{|c|}{4 wks postpartum } \\
\hline \multicolumn{6}{|c|}{ Supplement users + nonusers } \\
\hline Plasma folate & 53 & 28 & 44 & 28 & 0.1427 \\
\hline RBC folate & 53 & 40 & 40 & 20 & $<0.001$ \\
\hline \multicolumn{6}{|l|}{ Unsupplemented } \\
\hline Plasma folate & 17 & 18 & 41 & 41 & 0.2707 \\
\hline RBC folate & 17 & 35 & 30 & 35 & 0.0588 \\
\hline \multicolumn{6}{|c|}{16 wks postpartum } \\
\hline \multicolumn{6}{|c|}{ Supplement users + nonusers } \\
\hline Plasma folate & 55 & 47 & 33 & 20 & $<0.000$ I \\
\hline RBC folate & 55 & 33 & 43 & 24 & $<0.05$ \\
\hline \multicolumn{6}{|l|}{ Unsupplemented } \\
\hline Plasma folate & 18 & 6 & 50 & 44 & $<0.0001$ \\
\hline RBC folate & 18 & 22 & 39 & 39 & 0.7866 \\
\hline
\end{tabular}

I Percentage of participants misclassified by one quartile

2 Percentage of participants misclassified by two or more quartiles

${ }^{3} \mathrm{~A} P$-value $<0.05$ indicates a rejection of the null hypothesis that there is no association between folate intakes and blood folate concentration based on the expectation that $25 \%$ of participants would be correctly classified, $37.5 \%$ closely classified and $37.5 \%$ misclassified. The actual numbers are compared with expected numbers using chi-square goodness of fit with $2 \mathrm{df}$. 


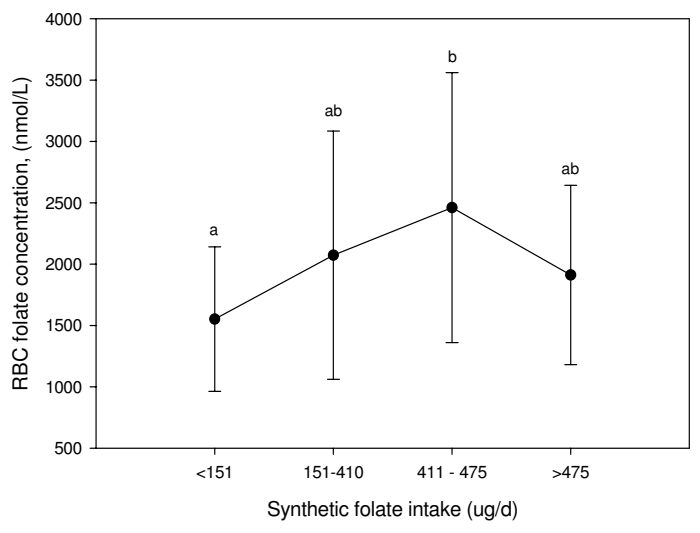

\section{Figure I}

Mean RBC folate concentrations ( \pm SD) by quartile of synthetic folate intake $(n=55)$ at 16 wk postpartum. Comparisons were made using one-way analysis of variance controlled for baseline RBC folate concentration (36 weeks gestation) and form of supplement provided during lactation (placebo, [6S]-5-methyl-THF, folic acid), and Tukeys multiple comparison procedures.

supply. In the present study, statistically significant correlations between dietary folate intake, as determined by 3 $\mathrm{d}$ weighed food records, and RBC folate, an indicator of NTD risk, at $4-(\mathrm{r}=0.32, P<0.05)$ and $16-\mathrm{wk}(\mathrm{r}=0.36, P$ $<0.01)$ postpartum were found. The strength of these associations are very similar to those recently reported between dietary folate intake, as assessed by an abbreviated folate-targeted food/supplement screening tool, and RBC folate concentration, in a sample of women from California ( $\mathrm{r}=0.32, P=0.0001)$ [35]. Neither the correlations reported in the present study nor those in the California report are stronger than those we previously reported pre-fortification in a group of young women from Southern Ontario $(\mathrm{r}=50, P<0.01)$ [26].

There are at least two likely explanations for our observations. First, the relationship between folate intake and blood folate concentration was no longer linear among lactating women in our study who for the most part had been chronically exposed to high levels of synthetic folate (Figure 1). Second, the quality of the food composition tables for folate is poor and, in fact their reflection of the "actual" folate concentration in foods may have deteriorated given the variability in mandated versus the actual levels of folic acid fortification. The actual folate content of the food supply in Canada is unknown. In 1998 when Health Canada mandated folic acid fortification of the food supply, they incorporated into the legislation an allowance for overages. In the U.S. where the food supply is also fortified with folic acid, overages are estimated to range from one to two times mandated levels [36-38]. In addition, the endogenous folate content of foods as listed in the version of the CNF used in our dietary analyses was determined prior to the use of the contemporary trienzyme folate extraction procedure; hence the quality of the folate values as listed in this database remains questionable and are very likely an underestimate of the true content of many foods. However, Han et al. too recently reported weak correlations between dietary folate intake and serum $(r=0.27)$ and RBC folate $(r=0.29)$ concentrations among healthy South Korean women despite the fact that they directly measured the folate content of most folate-containing foods after trienzyme extraction [39].

Regardless of the poor predictive ability of blood folate measures in assessing relative dietary folate intake in our study, it is clear that RBC folate concentrations in this group of affluent, well-educated lactating women are generally consistent with a reduction in risk of NTD (>906 $\mathrm{nmol} / \mathrm{L}$ ) as proposed by Daly and colleagues [16]. Using data from a large case-control study of 56,049 women, Daly et al reported a greater than eightfold difference in NTD risk between women with RBC folate concentrations less than $340 \mathrm{nmol} / \mathrm{L}$ compared with those with levels of $906 \mathrm{nmol} / \mathrm{L}$ or higher $(P<0.001)$ [16]. In fact, only two women in the present study had RBC folate concentrations $=906 \mathrm{nmol} / \mathrm{L}$ at 16 -wk postpartum; interestingly both were not consuming a folate-containing vitamin supplement during lactation. The RBC folate concentrations of these two women were 869 and $822 \mathrm{nmol} / \mathrm{L}$, which is well above cut-off values for classic folate deficiency $(363 \mathrm{nmol} / \mathrm{L})[20,34]$.

As reported elsewhere, however, approximately one-third of this sample of lactating women had dietary folate intakes (folate endogenous to food + folic acid as a fortificant) below their estimated average requirement [40]. Assuming that folic acid is being added to the food supply at mandated levels, the synthetic folate intakes of women in the present study increased by 147 and $118 \mu \mathrm{g} / \mathrm{d}$ folate at 4- and 16-wk postpartum, respectively, as a result of folic acid fortification of the food supply. Together with the blood folate values reported herein, these observations suggest that as lactation continues beyond 16-wks, a greater proportion of women not consuming a folate supplement may develop RBC folate concentrations $=906$ nmol/L. Subsequent to initiation of this study, Health Canada[41]., like the American Academy of Pediatrics [42] extended their recommended length of exclusive breastfeeding from 4-6 to 6 months (26 weeks). Thereafter, they recommend that infants receive complementary foods with continued breastfeeding through the first 12 months of life. In the present study, no women consuming a $400 \mu \mathrm{g} / \mathrm{d}$ folate supplement had a blood folate value $\leq 906 \mathrm{nmol} / \mathrm{L}$ or a folate intake below her estimated aver- 
age requirement [40]. As illustrated in Figure 1, in this sample of women, there didn't appear to be an advantage of synthetic folate intakes > 151-410 $\mu \mathrm{g} / \mathrm{d}$ in terms of maximizing RBC folate concentration. Considered together, then, these data suggest among well-nourished lactating women a folate supplement of $400 \mu \mathrm{g}$ consumed consistently on a daily basis maximizes RBC folate content, and strikes the right balance versus higher levels (eg. 1000 or $5000 \mu \mathrm{g} / \mathrm{d}$ ) of meeting the estimate average folate requirement of lactating women and not providing overly excessive amounts of folate than can not be incorporated into RBC precursors.

While these data are among the first to specifically assess how predictive blood folate concentrations and folate intakes are of each other post-folic acid fortification of the food supply, in addition to the quality of food composition tables, there are other limitations in estimating folate intake that must be acknowledged. Specifically, many women, particularly those that are overweight or concerned about their body weight, may under-report their dietary intake [43-45]. In addition, weighed food records, while generally regarded as the gold standard for determining dietary intakes may result in under-reporting of nutrient intake due to subject burden. Under-reporting and variability in measuring dietary intakes could have significantly weakened the statistical associations between folate intakes and blood folate concentrations in the present study. Both of the aforementioned issues could be of particular concern postpartum when many women have heightened awareness of their body weight and are busy with a new baby.

Finally, it should be noted that most lactating women in this study, on the advice of their primary care physician, consumed a $1000 \mu \mathrm{g} / \mathrm{d}$ supplement of folic acid during pregnancy. Many used the same folate-containing supplement prior to conception for NTD-prevention. While the life span of a RBC is 120 days and hence by 16-wk lactation should reflect dietary and supplemental folate intakes during lactation, the contribution of liver folate stores amassed prior to parturition in meeting the nutritional requirements beyond 16 weeks of lactation could be significant. The absence of an improvement in the association between blood folate concentrations and folate intake between 4 and 16 weeks lactation could reflect this phenomenon. While the incremental increase in liver folate stores secondary to ingestion of $1000 \mu \mathrm{g} / \mathrm{d}$ of supplemental folic acid during pregnancy is not known, visceral folate stores in the form of long-lived pteroylpolyglutamate pools can be converted to pteroylmonoglutamates which can then be released into circulation $[46,47]$.

\section{Conclusion}

In this sample of affluent well-nourished lactating Canadian women chronically exposed to high levels of folate, plasma and RBC folate concentrations were poor predictors of relative folate intake, estimated by food composition tables generally, and synthetic folic acid intake specifically. Synthetic intakes $>151-410 \mu \mathrm{g} / \mathrm{d}$ in these women produced little additional benefit in terms of maximizing RBC content. More studies are needed to examine the relationship between blood folate concentration and NTD risk. Until data from such studies are available, women planning a pregnancy should continue to consume a daily folic acid supplement of $400 \mu \mathrm{g}$.

\section{Competing interests}

The author(s) declare that they have no competing interests.

\section{Authors' contributions}

DLO and LAH were responsible for the design of the study and wrote the manuscript. LAH and KLS recruited the subjects and were responsible for the sample collection, laboratory analysis and statistical analysis. All authors read and approved the final manuscript.

\section{Acknowledgements}

We thank the Motherisk program at The Hospital for Sick Children for assisting with recruitment, Glynnis DuBois for lactation support, and the research nurses from the Clinical Investigation Unit for blood sample collection. We are grateful to all the mothers who participated in this project. This study was funded by Merck KGaA, Darmstadt, Germany and the Natural Sciences \& Engineering Research Council of Canada. LAH and KLS were funded by the Ontario Student Opportunity Trust Fund-The Hospital for Sick Children Scholarship Program and the Canadian Institute of Health Research Training Program in Clinical Nutrition.

\section{References}

I. MRC Vitamin Study Research Group: Prevention of neural tube defects: results of the Medical Research Council Vitamin Study. Lancet |99|, 338(8760): |3|-|37.

2. Berry RJ, Li Z, Erickson JD, Li S, Moore CA, Wang H, Mulinare J, Zhao P, Wong LY, Gindler J, et al.: Prevention of neural-tube defects with folic acid in China. China-U.S. Collaborative Project for Neural Tube Defect Prevention. N Engl J Med 1999, 34I(20): I 485-I 490.

3. Czeizel AE, Dudas I: Prevention of the first occurrence of neural-tube defects by periconceptional vitamin supplementation. N Engl J Med 1992, 327(26): 1832-1835.

4. Kirke PN, Daly LE, Elwood JH: A randomised trial of low dose folic acid to prevent neural tube defects. The Irish Vitamin Study Group. Arch Dis Child 1992, 67( I 2): I 442-I 446.

5. Laurence KM, James N, Miller MH, Tennant GB, Campbell H: Double-blind randomised controlled trial of folate treatment before conception to prevent recurrence of neural-tube defects. Br Med J (Clin Res Ed) I98I, 282(6275): I509-I5II .

6. French MR, Barr Sl, Levy-Milne R: Folate intakes and awareness of folate to prevent neural tube defects: a survey of women living in Vancouver, Canada. I Am Diet Assoc 2003, I03(2): $|8|-185$.

7. Liu S, West R, Randell E, Longerich L, O'Connor KS, Scott H, Crowley M, Lam A, Prabhakaran V, McCourt C: A comprehensive evaluation of food fortification with folic acid for the primary prevention of neural tube defects. BMC Pregnancy Childbirth 2004, 4(I):20. 
8. Morin P, De Wals P, St-Cyr-Tribble D, Niyonsenga T, Payette H: Pregnancy planning: a determinant of folic acid supplements use for the primary prevention of neural tube defects. Can J Public Health 2002, 93(4):259-263.

9. Morin P, De Wals P, Noiseux M, Niyonsenga T, St-Cyr-Tribble D, Tremblay C: Pregnancy planning and folic acid supplement use: results from a survey in Quebec. Prev Med 2002, 35(2): 143-149.

10. Canada Gazette. Part II: Regulatory impact analysis statement, SOR/98-550. 1998, 132:3029-3033.

II. Persad VL, Van den Hof MC, Dube JM, Zimmer P: Incidence of open neural tube defects in Nova Scotia after folic acid fortification. CMAJ 2002, 167(3):24I-245.

12. Pfeiffer CM, Caudill SP, Gunter EW, Osterloh J, Sampson E): Biochemical indicators of $B$ vitamin status in the US population after folic acid fortification: results from the National Health and Nutrition Examination Survey 1999-2000. Am J Clin Nutr 2005, 82(2):442-450.

13. Rader JI, Schneeman BO: Prevalence of neural tube defects, folate status, and folate fortification of enriched cereal-grain products in the United States. Pediatrics 2006, II 7(4): 1394-1399.

14. Ray, , , , , JG, Meier C, Vermeulen MJ, Boss S, Wyatt PR, Cole DE: Association of neural tube defects and folic acid food fortification in Canada. Lancet 2002, 360(9350):2047-8.

15. Houghton LA, Sherwood KL, Pawlosky R, Ito S, O'Connor DL: [6S]5-Methyltetrahydrofolate is at least as effective as folic acid in preventing a decline in blood folate concentrations during lactation. Am J Clin Nutr 2006, 83(4):842-850.

16. Daly LE, Kirke PN, Molloy A, Weir DG, Scott JM: Folate levels and neural tube defects. Implications for prevention. JAMA 1995, 274(2I):1698-1702.

17. Kirke PN, Molloy AM, Daly LE, Burke H, Weir DG, Scott JM: Maternal plasma folate and vitamin $B \mid 2$ are independent risk factors for neural tube defects. QJ Med 1993, 86(II):703-708.

18. Smithells RW, Sheppard S, Schorah CJ: Vitamin deficiencies and neural tube defects. Arch Dis Child 1976, 5 I ( 12):944-950.

19. van der Put NM, van Straaten HW, Trijbels FJ, Blom HJ: Folate, homocysteine and neural tube defects: an overview. Exp Biol Med (Maywood) 200I, 226(4):243-270.

20. Gibson RS: Assessment of folate and vitamin B/2 status. In Principles of Nutritional Assessment New York: Oxford University Press; 2005:595-640.

21. Guinotte CL, Burns MG, Axume JA, Hata H, Urrutia TF, Alamilla A, McCabe D, Singgih A, Cogger EA, Caudill MA: Methylenetetrahydrofolate reductase $677 \mathrm{C}-->T$ variant modulates folate status response to controlled folate intakes in young women. Nutr 2003, 133(5): 1272-1280.

22. Hung J, Yang TL, Urrutia TF, Li R, Perry CA, Hata H, Cogger EA, Moriarty DJ, Caudill MA: Additional food folate derived exclusively from natural sources improves folate status in young women with the MTHFR 677 CC or TT genotype. J Nutr Biochem 2006, I 7(I I):728-734.

23. Perry CA, Renna SA, Khitun E, Ortiz M, Moriarty DJ, Caudill MA: Ethnicity and race influence the folate status response to controlled folate intakes in young women. I Nutr 2004, I 34(7): I 786- I 792.

24. Shelnutt KP, Kauwell GP, Chapman CM, Gregory JF 3rd, Maneval DR, Browdy AA, Theriaque DW, Bailey LB: Folate status response to controlled folate intake is affected by the methylenetetrahydrofolate reductase $677 \mathrm{C}-->\mathrm{T}$ polymorphism in young women. J Nutr 2003, I 33( I 2):4 I07-4IIII.

25. Yang TL, Hung Y, Caudill MA, Urrutia TF, Alamilla A, Perry CA, Li R, Hata $H$, Cogger EA: A long-term controlled folate feeding study in young women supports the validity of the $1.7 \mathrm{mul}$ tiplier in the dietary folate equivalency equation. J Nutr 2005 , 135(5): I 139-45.

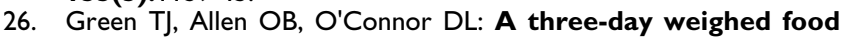
record and a semiquantitative food-frequency questionnaire are valid measures for assessing the folate and vitamin B-12 intakes of women aged 16 to 19 years. J Nutr 1998, I 28(10): | 665-|67|

27. Institute of Medicine: Folate. In Dietary reference intakes for Thiamin Riboflavin, Niacin, Vitamin B6, Folate, Vitamin B I2, Pantothenic acid, Biotin and Choline Washington, DC: The National Academy Press: 1998:196-305.
28. Canadian Institute of Health Research, Natural Sciences and Engineering Research Council of Canada, Social Sciences and Humanities Research Council of Canada. Tri-council policy statement: Ethical conduct for research involving humans. Ottawa: Public Works and Government Services; 1998.

29. Molloy AM, Scott JM: Microbiological assay for serum, plasma, and red cell folate using cryopreserved, microtiter plate method. Methods Enzymol 1997, 28 1:43-53.

30. Cole DE, Lehotay DC, Evrovski J: Simplified simultaneous assay of total plasma homocysteine and methionine by HPLC and pulsed integrated amperometry. Clin Chem 1998, 44(I): $188-190$

31. Health Canada: Canadian Nutrient File (CNF). 200I [http:// www.hc-sc.gc.ca/food-aliment/ns-sc/nr-rn/surveillance/cnf-fcen/ e cnf downloads.html].

32. United States Department of Agriculture, Agricultural Research Service: USDA National Nutrient Databse for Standard Reference. 2005 [http://www.ars.usda.gov/ba/bhnrc/ndl].

33. Statistics Canada: Median total income, by family type, by province and territory. Version 4. August 2006. 2006 [http:// www40.statcan.ca/l0I/cst0l/famill 08a.htm].

34. Herbert V: Development of human folate deficiency. In Folic acid metabolism in health and disease Edited by: Picciano MF, Stokstad EL, Gregory JF, 3rd. New York: Wiley; 1990:195-210

35. Clifford AJ, Noceti EM, Block-Joy A, Block T, Block G: Erythrocyte folate and its response to folic acid supplementation is assay dependent in women. J Nutr 2004, 135(I): 137-143.

36. Johnston KE, Tamura T: Folate content in commercial white and whole wheat sandwich breads. J Agric Food Chem 2004, 52(20):6338-6340.

37. Quinlivan EP, Gregory JF 3rd: Effect of food fortification on folic acid intake in the United States. Am J Clin Nutr 2003, 77(I):22I-225.

38. Rader JI, Weaver CM, Angyal G: Total folate in enriched cerealgrain products in the United States following fortification. Food Chem 2000, 70:275-289.

39. Han $\mathrm{YH}$, Yon M, Hyun TH: Folate intake estimated with an updated database and its association to blood folate and homocysteine in Korean college students. Eur J Clin Nutr 2005, 59(2):246-54

40. Sherwood KL, Houghton LA, Tarasuk V, O'Connor DL: One-third of pregnant and lactating women may not be meeting their folate requirements from diet alone based on mandated levels of folic acid fortification. J Nutr 2006, I 36(II):2820-2826

41. Health Canada: Exclusive Breastfeeding Duration - 2004 Health Canada Recommendation. 2004 [http://www.hcsc.gc.ca/fn-an/nutrition/child-enfant/infant-nourisson/excl bf durdur am excl e.html].

42. American Academy of Pediatrics: Breastfeeding and the use of human milk. Pediatrics 2005, I I 5:496-506.

43. Becker W, Welten D: Under-reporting in dietary surveys implications for development of food-based dietary guidelines. Public Health Nutr 200I, 4(2B):683-687.

44. Bingham SA, Cassidy A, Cole TJ, Welch A, Runswick SA, Black AE, Thurnham D, Bates C, Khaw KT, Key TJ, et al: Validation of weighed records and other methods of dietary assessment using the $24 \mathrm{~h}$ urine nitrogen technique and other biological markers. Br J Nutr 1995, 73(4):531-550.

45. Black AE, Cole TJ: Biased over- or under-reporting is characteristic of individuals whether over time or by different assessment methods. J Am Diet Assoc 200 I, I0 I ( I):70-80.

46. Lin Y, Dueker SR, Follett JR, Fadel JG, Arjomand A, Schneider PD, Miller JW, Green R, Buchholz BA, Vogel JS, et al.: Quantitation of in vivo human folate metabolism. Am J Clin Nutr 2004, 80(3):680-69l.

47. Suh JR, Herbig AK, Stover PJ: New perspectives on folate catabolism. Annu Rev Nutr 200 I, 2 I:255-282.

\section{Pre-publication history}

The pre-publication history for this paper can be accessed here:

http://www.biomedcentral.com/1471-2393/7/25/prepub 